九州大学学術情報リポジトリ

Kyushu University Institutional Repository

\title{
Exploration on Filamentous Phenotype of Coprinus comatus Colleted form Different Ecological Origins
}

Imtiaj, Ahmed

Lee, Tae-Soo

Department of Biology, University of Incheon

Ohga, Shoji

Laboratory of Forest Resources Management, Division of Forest Ecosphere Management, Department of Forest and Forest Products Sciences, Kyushu University

https://doi.org/10.5109/18830

出版情報 : 九州大学大学院農学研究院紀要. 55 (2)，pp. 203-207，2010-10-29. Faculty of Agriculture, Kyushu University

バージョン：

権利関係 : 


\title{
Exploration on Filamentous Phenotype of Coprinus comatus Colleted form Different Ecological Origins
}

\author{
Ahmed IMTIAJ, Tae-Soo LEE ${ }^{1}$ and Shoji OHGA* \\ Laboratory of Forest Resources Management, Division of Forest Environmental Sciences, \\ Department of Agro-environmental Sciences, Faculty of Agricultare, \\ Kyushu University, Fukuoka 811-2415, Japan \\ (Received May 20, 2010 and accepted July 9, 2010)
}

\begin{abstract}
Coprinus comatus is an edible and nematophagous basidiomycete fungus. The optimal culture conditions for the filamentous growth and density of 6 strains of this mushroom were investigated. The temperature suitable for the filamentous growth and density was obtained at $25^{\circ} \mathrm{C}$ and optimal range of temperature was $20 \sim 30^{\circ} \mathrm{C}$. This mushroom showed a broad $\mathrm{pH}$ range (5 9) for its mycelial growth and density. The mostly favorable growth was found at $\mathrm{pH}$ 7. According to filamentous growth Czapek's, PDA, YM, and Hamada were the most suitable, and Hennerberg and Hoppkins were the most unfavorable for this mushroom. Among 10 different carbon sources, sucrose and sorbitol were the best but lactose and xylose were the most unfavorable carbon sources. In all carbon sources, mycelial density was found to be compact. The most suitable nitrogen source was arginine and glycine but the most unsuitable was histidine for the mycelial growth. The mycelial density in nitrogen source containing medium was found to be different on the culture media.
\end{abstract}

\section{INTRODUCTION}

Coprinus comatus is a nematophagous basidiomycete mushroom. It is often seen growing on lawns, along gravel roads and waste areas. This fungus is called 'shaggy ink cap' or 'shaggy mane' and cultivated in China as food. The genus 'Coprinus' was formerly considered to be a large one with well over 100 species and its specific name derives from coma or hair, hence comatus, 'haired' or 'shaggy'. The young mushroom, before the gills start to turn black, is edible. The young fruiting bodies first appear as white cylinders emerging from the ground and then the bell-shaped caps open out. The caps are covered with scales that are the origin of the common names of the fungus. The gills secrete a black liquid filled with spores which considered as nematode killing device (Tzean and Liou, 1993). A recent study has found the shaggy ink cap kills nematode species Panagrellus redivivus and Meloidogyne arenaria. $C$. comatus is shown to be a nematode destroying fungus, producing a new structure designated spiny ball. The infection process of $P$. redivivus by the fungus is already studied (Luo et al., 2004). Similar secretory appendages were found on lawn mushroom Conocybe lacteal, in which they are more likely to be defense apparatus. After paralyzing and killing nematodes, $C$. lacteal does not use them as food (Hutchison et al., 1995). The wood-decay fungi obtain nitrogen supplement from prey, including nematodes, to survive in such nitrogen-restricted habitat as rotting wood and forest soil (Thorn and Barron, 1984 \& 1986). Along the hyphae of these nematophagous basidiomycete fungi, some appendages were found to be attack or defense weap-

\footnotetext{
1 Department of Biology, University of Incheon, Incheon 402749, Korea

* Corresponding author (E-mail: ohga@forest.kyushu-u.ac.jp)
}

ons.

Based on these significances, a study has been conducted on the mycelial growth and density of 6 strains of C. comatus. The different environmental and nutritional factors were used to assess the optimal culture conditions for the mycelial growth and density of this fungus and presented in this paper.

\section{MATERIALS AND METHODS}

\section{Collection, identification and isolation}

The fruiting bodies of 6 strains of Coprinus comatus were collected from different regions of Korea and China shown in Table 1. After identification mycelia were isolated, cultured on potato dextrose agar (PDA) medium and incubated at $25{ }^{\circ} \mathrm{C}$ for further study. The pure cultures of mushroom were deposited in 'Culture Collection of Wild Mushroom (CCWM)' and acquired accession number from University of Incheon Mushroom (IUM). All of the strains used in different experiments were performed with 3 replications.

Table 1. List of $C$. comatus strains used in this study

\begin{tabular}{lll}
\hline Strain No. & Geographical origin & \multicolumn{1}{c}{ Collection date } \\
\hline IUM 0004 & Seaside, Korea & September 3, 2005 \\
IUM 0707 & Bupyeong-dong, Korea & July 2, 2003 \\
IUM 0756 & Incheon, Korea & May 7, 2002 \\
IUM 1544 & Beijing, China & February 24, 2005 \\
IUM 1573 & SangHai, China & April 11, 2005 \\
IUM 1820 & Beijing, China & August 14,2005 \\
\hline
\end{tabular}

\section{Effect of temperature}

To detect the suitable temperature for the mycelial growth of the mushroom, 5 different temperatures were studied. A $5 \mathrm{~mm}$ diameter agar plug removed from 10 days old culture grown on PDA and placed in the centre 
of each plate filled with $20 \mathrm{ml}$ of PDA. The medium was adjusted to $\mathrm{pH} 6$ and incubated for 10 days at $15^{\circ} \mathrm{C}, 20^{\circ} \mathrm{C}$, $25{ }^{\circ} \mathrm{C}, 30^{\circ} \mathrm{C}$ and $35^{\circ} \mathrm{C}$ separately. The measurement of mycelial growth was performed according to the method described by Shim et al. (1997).

\section{Effect of pH}

A agar plug of $5 \mathrm{~mm}$ diameter of an inoculum was removed with cork borer from 10 days old culture grown on PDA was placed in the centre of each agar plate. The medium was adjusted to $\mathrm{pH}$ of 5, 6, 7, 8 and 9 with the addition of $1 \mathrm{~N} \mathrm{NaOH}$ or $\mathrm{HCl}$ and incubated at $25^{\circ} \mathrm{C}$ for 10 days. The mycelial growth was also measured according to the method described by Shim et al. (1997).

\section{Screening of favorable culture media}

Ten different culture media were prepared to investigate the mycelial growth of used mushroom strains (Table 2). The media were adjusted to $\mathrm{pH} 6$ before autoclave. After autoclave for 15 minutes at $121^{\circ} \mathrm{C}, 20 \mathrm{ml}$ of each medium was aseptically poured into a plate. A 5 mm diameter plug of an inoculum was removed from 10 days old culture grown on PDA and placed in the centre of each plate of 10 different culture media. After 10 days of incubation at $25^{\circ} \mathrm{C}$, mycelial growth and density was measured.

\section{Effect of carbon and nitrogen}

To test out carbon and nitrogen source favorable for the mycelial growth of mushroom strains, the tests were conducted on the basal medium supplemented with each of 10 carbon and 10 nitrogen sources separately. The basal medium was composed of $\mathrm{MgSO}_{4} 0.05 \mathrm{~g}, \mathrm{KH}_{2} \mathrm{PO}_{4}$ $0.46 \mathrm{~g}, \mathrm{~K}_{2} \mathrm{HPO}_{4} 1.0 \mathrm{~g}$, thiamine-HCl $120 \mu \mathrm{g}$, agar $20 \mathrm{~g}$ and $1000 \mathrm{ml}$ of distilled water. To screen carbon source favorable to the mycelial growth, each carbon source with $5 \mathrm{~g}$ of peptone was added to the basal medium separately at the concentration of $0.1 \mathrm{M}$ per $1000 \mathrm{ml}$ and mixed thoroughly (Shim et al., 1997). The basal medium which was used for screening a favorable nitrogen source was made of same additives as those described by Sung et al. (1993). Each nitrogen source with $20 \mathrm{~g}$ of glucose was added to the basal medium at the concentration of $0.02 \mathrm{M}$ (Shim et al., 1997). In both cases the basal medium was adjusted to $\mathrm{pH} 6$ before autoclave for 15 minutes at $121^{\circ} \mathrm{C}$ and poured into a plate. To measure colony diameter of mycelia on the media, all plates were incubated for 10 days at $25^{\circ} \mathrm{C}$. After incubation, mycelial radial growth and density was measured following same manner.

\section{RESULTS AND DISCUSSION}

\section{Effect of temperature}

Temperature suitable for the mycelial growth and density of tested fungal strains was obtained at $25^{\circ} \mathrm{C}$. The strain IUM0756 showed an exceptional mycelial growth where the highest was counted at $15^{\circ} \mathrm{C}$. No mycelial growth (except IUM0707) was found at $35^{\circ} \mathrm{C}$ and the lowest mycelial growth was recorded at $30^{\circ} \mathrm{C}$. The optimal range of temperature was $20 \sim 30^{\circ} \mathrm{C}$ for mycelial growth and density of $C$. comatus. In every case of temperature effect, mycelial density was found to be compact (Table 3). Lee et al. (1999) and Shim et al.

Table 2. Media and their compositions used in this study

\begin{tabular}{|c|c|c|c|c|c|c|c|c|c|c|}
\hline \multirow{2}{*}{ Composition } & \multicolumn{10}{|c|}{ Media (g/l) } \\
\hline & $\mathrm{Cza}$ & Ham & Hen & Hop & GP & GT & Lil & $\mathrm{MC}$ & PDA & YM \\
\hline Agar & 20 & 20 & 20 & 20 & 20 & 20 & 20 & 20 & 20 & 20 \\
\hline Dextrose & & 10 & & & & & & & 20 & 10 \\
\hline Ebiose & & 5 & & & & & & & & \\
\hline Malt-extract & & & & & 15 & & & 20 & & 3 \\
\hline Maltose & & & & & & & 10 & & & \\
\hline Peptone & & & & & 10 & & & 2 & & 5 \\
\hline Potatoes & & & & & & & & & 200 & \\
\hline $\mathrm{K}_{2} \mathrm{HPO}_{4}$ & 1 & & & & & & & 1 & & \\
\hline $\mathrm{MgSO}_{4}$ & 0.5 & & 0.5 & 0.5 & & & 0.5 & 0.5 & & \\
\hline $\mathrm{KCl}$ & 0.5 & & & & & & & & & \\
\hline $\mathrm{FeSO}_{4}$ & 0.01 & & & & & & & & & \\
\hline $\mathrm{CaCl}_{2}$ & & & 0.1 & & & & & & & \\
\hline $\mathrm{KH}_{2} \mathrm{PO}_{4}$ & & & 1 & 0.1 & & & 1 & 0.5 & & \\
\hline $\mathrm{KNO}_{3}$ & & & 2 & 2 & & & & & & \\
\hline
\end{tabular}

Cza: czapek's, Ham: hamada, Hen; hennerberg, Hop: hoppkins, GP: glucose peptone, GT: glucose tryptone, Lil: lilly. MC: mushroom complete, PDA: potato dextrose agar and YM: yeast-malt extract 
Table 3. Effect of temperatures and $\mathrm{pH}$ on the mycelial growth and density of different strains of $C$. comatus

\begin{tabular}{|c|c|c|c|c|c|c|c|c|c|c|}
\hline \multirow{3}{*}{ Strain } & \multicolumn{10}{|c|}{ Mycelial growth (mm) and density } \\
\hline & \multicolumn{5}{|c|}{ Temperature } & \multicolumn{5}{|c|}{$\mathrm{pH}$} \\
\hline & $15^{\circ} \mathrm{C}$ & $20^{\circ} \mathrm{C}$ & $25^{\circ} \mathrm{C}$ & $30^{\circ} \mathrm{C}$ & $35^{\circ} \mathrm{C}$ & 5 & 6 & 7 & 8 & 9 \\
\hline IuM 0004 & $13.7 \pm 1.5 \mathrm{c}$ & $15.0 \pm 2.6 \mathrm{c}$ & $19.3 \pm 2.3 \mathrm{c}$ & $10.7 \pm 1.2 \mathrm{c}$ & - & $35.0 \pm 4.4 \mathrm{c}$ & $54.3 \pm 5.5 c$ & $59.7 \pm 8.6 c$ & $52.0 \pm 7.1 \mathrm{c}$ & $48.0 \pm 9.3 \mathrm{c}$ \\
\hline IUM 0707 & $72.0 \pm 1.7 \mathrm{c}$ & $83.0 \pm 1.0 \mathrm{c}$ & $87.0 \pm 0.0 \mathrm{c}$ & $87.0 \pm 0.0 \mathrm{c}$ & $11.3 \pm 0.6 \mathrm{c}$ & $37.7 \pm 2.5 c$ & $87.0 \pm 0.0 \mathrm{c}$ & $87.0 \pm 0.0 \mathrm{c}$ & $86.0 \pm 1.7 \mathrm{c}$ & $83.3 \pm 3.5 c$ \\
\hline IUM 0756 & $28.0 \pm 2.0 \mathrm{c}$ & $24.3 \pm 4.5 \mathrm{c}$ & $24.0 \pm 1.0 \mathrm{c}$ & $14.7 \pm 1.5 \mathrm{c}$ & - & $16.7 \pm 2.5 \mathrm{c}$ & $22.7 \pm 0.6 \mathrm{c}$ & $22.7 \pm 1.5 \mathrm{c}$ & $22.0 \pm 1.7 \mathrm{c}$ & $20.7 \pm 2.3 \mathrm{c}$ \\
\hline IUM 1544 & $43.7 \pm 1.2 \mathrm{c}$ & $51.7 \pm 8.0 \mathrm{c}$ & $80.0 \pm 0.0 c$ & $66.0 \pm 7.9 \mathrm{c}$ & - & $29.0 \pm 2.6 c$ & $69.0 \pm 9.0 \mathrm{c}$ & $75.0 \pm 0.0 \mathrm{c}$ & $58.3 \pm 4.5 c$ & $45.3 \pm 4.5 \mathrm{c}$ \\
\hline IUM 1573 & $46.7 \pm 5.8 \mathrm{c}$ & $54.3 \pm 1.2 \mathrm{c}$ & $57.3 \pm 8.1 \mathrm{c}$ & $31.7 \pm 4.7 \mathrm{c}$ & - & $34.7 \pm 4.6 \mathrm{c}$ & $53.3 \pm 8.0 \mathrm{c}$ & $58.3 \pm 8.5 c$ & $51.3 \pm 8.2 \mathrm{c}$ & $47.7 \pm 9.5 \mathrm{c}$ \\
\hline IUM 1820 & $33.0 \pm 3.0 \mathrm{c}$ & $36.3 \pm 2.3 \mathrm{c}$ & $58.3 \pm 9.8 c$ & $15.3 \pm 6.7 \mathrm{c}$ & - & $42.3 \pm 1.2 \mathrm{c}$ & $79.7 \pm 4.2 \mathrm{c}$ & $79.7 \pm 9.0 \mathrm{c}$ & $79.3 \pm 3.2 \mathrm{c}$ & $63.0 \pm 1.0 \mathrm{c}$ \\
\hline
\end{tabular}

${ }^{a}$ Mean of three replications. Temperature and $\mathrm{pH}$ effects were conducted in potato dextrose agar medium (PDA). c: Compact. sc:

Somewhat compact. st: Somewhat thin and t: Thin

(2003) reported that the mycelial growth of Paecilomyces fumosoroseus had been expedited gradually in proportion to the rise of temperature and the most suitable was at $25^{\circ} \mathrm{C}$. Even though the mycelial growth of $P$. fumosoroseus was favorable at the range of $20 \sim 25^{\circ} \mathrm{C}$ and had been expedited in proportion to the rise of temperature, the mycelial growth appeared to be suppressed at the temperature higher than $30^{\circ} \mathrm{C}$. Shim et al. (2005) and Jo et al. (2006) stated that the favorable mycelial growth of Macrolepiota procera and Phellinus spp. was at $30{ }^{\circ} \mathrm{C}$. Therefore, these results are corresponded with that of our findings.

\section{Effect of pH}

To monitor $\mathrm{pH}$ value suitable for the favorable growth and density of $C$. comatus, it was observed at the range of $5 \sim 9$ and the best was pH 7. In case of IUM0707 and IUM0756, the highest growth was also appeared 87.0 and $22.7 \mathrm{~mm}$ at $\mathrm{pH} 6$, respectively. Rest of the temperatures was also showed good mycelial growth of different strains of $C$. comatus. In every case of used $\mathrm{pH}$, mycelial density was found to be compact (Table 3). Shim et al. (2005) revealed that $\mathrm{pH} 7$ is the most suitable for the optimal growth of M. procera. Choi et al. (1999) and Chi et al. (1996) reported that mycelial growth of Phellinus japonica and $P$. linteus was optimal at $\mathrm{pH} 7$ and $6 \sim 7$, respectively. Shim et al. (2003) shown that optimal pH of Paecilomyces sinclairii was 8. Shim et al. (1997) also reported that the most favorable and most unfavorable pH of Grifola umbellata was 4 and 9, respectively. This result suggested that mushrooms may have a broad $\mathrm{pH}$ range for their optimal mycelial growth in nature.
The results of this study is completely similar to Shim et al. (2005), Choi et al. (1999) and Chi et al. (1996) but not similar to Shim et al. (2003 \& 1997).

\section{Screening of favorable culture media}

Ten different culture media were used to display the optimal mycelial growth of different strains of $C$. comatus. The highest mycelial growth of IUM0004 and IUM0756 was 30.3 and $31.7 \mathrm{~mm}$ on Hamada medium, respectively. Rests of the strains were showed the best mycelial growth in YM and Czapeck's media. According to mycelial growth Czapek's, PDA, YM, and Hamada were the most suitable, and Hennerberg and Hoppkins were the most unfavorable for mycelial growth of $C$. comatus (Table 4). Besides of slow growth, mycelial density was also somewhat thin to thin on Czapek's, and Hoppkins media. This result is corresponded with that of $P$. sinclairii and $P$. fumosoroseus which had been reported by Shim et al. (2003) where mycelial growth was optimal on Hamada medium. Shim et al. (2005) also reported that PDA, YM, Mushroom complete and Hamada were the most suitable, where Czapex dox and Glucose peptone were unfavorable to mycelial growth of $M$. procera.

\section{Effect of carbon sources}

Ten different carbon sources were used to find out the optimal culture condition. The best carbon sources for the suitable mycelial growth were sucrose and sorbitol but unfavorable were lactose and xylose. All of the carbon sources showed compact mycelial density of $C$. comatus (Table 5). This result is completely similar to

Table 4. Effect of media on the mycelial growth and density of different strains of $C$. comatus

\begin{tabular}{|c|c|c|c|c|c|c|c|c|c|c|}
\hline \multirow{2}{*}{ Strain } & \multicolumn{10}{|c|}{ Mycelial growth (mm) a and density } \\
\hline & $\mathrm{Cza}$ & Ham & Hen & Hop & GP & GT & Lil & $\mathrm{MC}$ & PDA & YM \\
\hline IUM 0004 & $28.7 \pm 1.2 \mathrm{st}$ & $30.3 \pm 2.5 c$ & $15.7 \pm 1.2 \mathrm{c}$ & $23.0 \pm 1.0 \mathrm{t}$ & $25.7 \pm 1.2 \mathrm{c}$ & $24.7 \pm 3.5 \mathrm{c}$ & $23.3 \pm 4.2 \mathrm{c}$ & $23.3 \pm 1.5 \mathrm{c}$ & $27.1 \pm 2.1 \mathrm{c}$ & $22.0 \pm 1.0 \mathrm{c}$ \\
\hline IUM 0707 & $87.0 \pm 0.0 \mathrm{t}$ & $87.0 \pm 0.0 \mathrm{c}$ & $59.0 \pm 1.0 \mathrm{c}$ & $87.0 \pm 0.0 \mathrm{t}$ & $87.0 \pm 0.0 \mathrm{c}$ & $87.0 \pm 0.0 \mathrm{c}$ & $87.0 \pm 0.0 \mathrm{c}$ & $87.0 \pm 0.0 \mathrm{c}$ & $87.0 \pm 0.0 \mathrm{c}$ & $87.0 \pm 0.0 \mathrm{c}$ \\
\hline IUM 0756 & $29.7 \pm 1.2 \mathrm{st}$ & $31.7 \pm 2.5 \mathrm{c}$ & $15.8 \pm 1.1 \mathrm{c}$ & $23.2 \pm 1.0 \mathrm{t}$ & $24.7 \pm 3.2 \mathrm{c}$ & $25.7 \pm 3.5 \mathrm{c}$ & $23.3 \pm 4.2 \mathrm{c}$ & $24.3 \pm 2.5 \mathrm{c}$ & $25.0 \pm 2.0 \mathrm{c}$ & $23.0 \pm 3.0 \mathrm{c}$ \\
\hline IUM 1544 & $82.7 \pm 4.0 \mathrm{t}$ & $47.3 \pm 2.5 \mathrm{c}$ & $39.7 \pm 8.7 \mathrm{c}$ & $45.0 \pm 2.6 \mathrm{t}$ & $58.3 \pm 7.0 \mathrm{c}$ & $54.3 \pm 4.0 \mathrm{c}$ & $44.7 \pm 9.6 \mathrm{c}$ & $77.0 \pm 2.6 \mathrm{c}$ & $80.0 \pm 0.0 c$ & $82.3 \pm 0.6 c$ \\
\hline IUM 1573 & $71.3 \pm 8.5 \mathrm{st}$ & $44.7 \pm 0.6 \mathrm{c}$ & $40.7 \pm 2.1 \mathrm{c}$ & $40.7 \pm 3.5 \mathrm{t}$ & $47.0 \pm 2.6 \mathrm{c}$ & $56.3 \pm 8.0 \mathrm{c}$ & $43.7 \pm 1.5 \mathrm{c}$ & $53.3 \pm 9.1 \mathrm{c}$ & $57.3 \pm 8.1 \mathrm{c}$ & $74.0 \pm 7.9 \mathrm{c}$ \\
\hline IUM 1820 & $84.3 \pm 3.1 \mathrm{st}$ & $47.7 \pm 4.6 \mathrm{c}$ & $74.3 \pm 7.4 \mathrm{c}$ & $37.3 \pm 3.2 \mathrm{st}$ & $78.3 \pm 9.6 c$ & $85.3 \pm 2.9 c$ & $47.0 \pm 6.1 \mathrm{c}$ & $79.7 \pm 3.5 c$ & $58.3 \pm 6.8 \mathrm{c}$ & $85.7 \pm 1.5 c$ \\
\hline
\end{tabular}

${ }^{a}$ Mean of three replications. Cza: czapek's. Ham: hamada. Hen: hennerberg. Hop: hoppkins. GP: glucose peptone. GT: glucose tryptone. Lil: lilly. MC: mushroom complete. PDA: potato dextrose agar and YM: yeast-malt extract. c: Compact. sc: Somewhat compact. st: Somewhat thin and t: Thin 
Table 5. Effect of carbon sources on the mycelial growth and density of different strains of C. comatus

\begin{tabular}{|c|c|c|c|c|c|c|c|c|c|c|}
\hline \multirow{2}{*}{ Strain } & \multicolumn{10}{|c|}{ Mycelial growth $(\mathrm{mm})^{\mathrm{a}}$ and density } \\
\hline & Dex & $\mathrm{Fr}$ & $\mathrm{Ga}$ & $\mathrm{Gl}$ & Lac & Mal & Man & Sor & Sur & Xy \\
\hline IUM 0004 & $31.0 \pm 1.7 \mathrm{c}$ & $32.0 \pm 1.0 \mathrm{c}$ & $24.0 \pm 1.0 \mathrm{c}$ & $31.0 \pm 1.0 \mathrm{c}$ & $21.3 \pm 0.6 \mathrm{c}$ & $32.0 \pm 2.6 c$ & $30.3 \pm 1.5 c$ & $30.0 \pm 1.0 \mathrm{c}$ & $37.7 \pm 2.9 \mathrm{c}$ & $20.3 \pm 1.2 \mathrm{c}$ \\
\hline IUM 0707 & $76.0 \pm 1.7 \mathrm{c}$ & $86.3 \pm 1.2 \mathrm{c}$ & $74.0 \pm 0.0 \mathrm{c}$ & $87.0 \pm 0.0 \mathrm{c}$ & $48.0 \pm 0.0 \mathrm{c}$ & $87.0 \pm 0.0 c$ & $87.0 \pm 0.0 \mathrm{c}$ & $87.0 \pm 0.0 c$ & $87.0 \pm 0.0 \mathrm{c}$ & $77.0 \pm 0.0 \mathrm{c}$ \\
\hline IUM 0756 & $33.3 \pm 1.5 \mathrm{c}$ & $33.7 \pm 1.2 \mathrm{c}$ & $23.3 \pm 1.2 \mathrm{c}$ & $30.7 \pm 1.2 \mathrm{c}$ & $21.0 \pm 1.7 \mathrm{c}$ & $31.7 \pm 2.9 \mathrm{c}$ & $30.3 \pm 0.6 c$ & $29.0 \pm 1.0 \mathrm{c}$ & $38.3 \pm 3.5 \mathrm{c}$ & $19.0 \pm 1.0 \mathrm{c}$ \\
\hline IUM 1544 & $64.3 \pm 3.1 \mathrm{c}$ & $79.7 \pm 5.8 \mathrm{c}$ & $54.0 \pm 8.7 \mathrm{c}$ & $87.0 \pm 0.0 c$ & $32.0 \pm 5.3 \mathrm{c}$ & $87.0 \pm 0.0 c$ & $86.0 \pm 1.7 \mathrm{c}$ & $87.0 \pm 0.0 c$ & $87.0 \pm 0.0 \mathrm{c}$ & $33.3 \pm 4.2 \mathrm{c}$ \\
\hline IUM 1573 & $51.3 \pm 4.0 \mathrm{c}$ & $75.0 \pm 9.0 \mathrm{c}$ & $29.7 \pm 8.5 c$ & $77.7 \pm 4.6 \mathrm{c}$ & $18.0 \pm 3.6 \mathrm{c}$ & $84.0 \pm 2.6 c$ & $69.7 \pm 4.7 \mathrm{c}$ & $87.0 \pm 0.0 c$ & $87.0 \pm 0.0 \mathrm{c}$ & $24.3 \pm 1.2 \mathrm{c}$ \\
\hline IUM 1820 & $37.3 \pm 4.6 \mathrm{c}$ & $42.7 \pm 7.5 c$ & $52.7 \pm 5.4 \mathrm{c}$ & $52.0 \pm 9.9 c$ & $19.7 \pm 3.8 \mathrm{c}$ & $70.7 \pm 4.0 \mathrm{c}$ & $51.3 \pm 4.2 \mathrm{c}$ & $87.0 \pm 0.0 c$ & $79.3 \pm 3.5 \mathrm{c}$ & $61.0 \pm 6.0 \mathrm{c}$ \\
\hline
\end{tabular}

${ }^{a}$ Mean of three replications. Dex: dextrin. Fr: fructose. Ga: galactose. Gl: glucose. Lac: lactose. Mal: maltose. Man: mannose. Sor: sorbitol. Suc: sucrose and Xy: xylose. Each carbon source was added to the basal medium at the concentration of 0.1 M. c: Compact. sc: Somewhat compact. st: Somewhat thin and t: Thin

Table 6. Effect of nitrogen sources on the mycelial growth and density of different strains of C. comatus

\begin{tabular}{|c|c|c|c|c|c|c|c|c|c|c|}
\hline \multirow{2}{*}{ Strain } & \multicolumn{10}{|c|}{ Mycelial growth (mm) and density } \\
\hline & Ala & $\mathrm{AA}$ & $\mathrm{AP}$ & Arg & $\mathrm{CN}$ & Gly & His & Met & $\mathrm{PN}$ & $\mathrm{Ur}$ \\
\hline IUM 0004 & $17.3 \pm 4.0 \mathrm{c}$ & $26.0 \pm 7.8 c$ & $26.3 \pm 5.5 c$ & $29.3 \pm 4.9 \mathrm{c}$ & $34.0 \pm 6.2 \mathrm{c}$ & $31.0 \pm 1.0 \mathrm{c}$ & $5.7 \pm 4.9 \mathrm{sc}$ & $23.0 \pm 2.0 \mathrm{sc}$ & $19.0 \pm 6.6 \mathrm{c}$ & $20.7 \pm 9.3 \mathrm{c}$ \\
\hline IUM 0707 & $70.0 \pm 8.0 \mathrm{st}$ & $73.7 \pm 6.0 \mathrm{sc}$ & $39.7 \pm 2.5 s t$ & $44.7 \pm 8.1 \mathrm{sc}$ & $69.7 \pm 4.9 \mathrm{c}$ & $87.0 \pm 0.0 \mathrm{c}$ & - & $87.0 \pm 0.0 \mathrm{t}$ & $85.3 \pm 1.5 \mathrm{t}$ & $29.3 \pm 6.0$ st \\
\hline IUM 0756 & $18.7 \pm 1.2 \mathrm{c}$ & $22.7 \pm 3.1 c$ & $22.7 \pm 3.8 c$ & $24.0 \pm 1.7 \mathrm{c}$ & $27.3 \pm 4.2 \mathrm{c}$ & $31.3 \pm 1.2 \mathrm{c}$ & - & $23.7 \pm 1.2 \mathrm{sc}$ & $24.3 \pm 4.0 \mathrm{c}$ & $12.3 \pm 0.6 \mathrm{c}$ \\
\hline IUM 1544 & $23.0 \pm 3.0 \mathrm{c}$ & $54.7 \pm 0.6 c$ & $46.3 \pm 7.6 \mathrm{c}$ & $72.7 \pm 7.9 c$ & $40.7 \pm 9.3 \mathrm{c}$ & $70.7 \pm 7.1 \mathrm{c}$ & $14.7 \pm 2.9 \mathrm{sc}$ & $38.7 \pm 1.2 \mathrm{sc}$ & $62.7 \pm 4.6 \mathrm{c}$ & $87.0 \pm 0.0 \mathrm{c}$ \\
\hline IUM 1573 & $15.0 \pm 2.0 \mathrm{c}$ & $33.7 \pm 1.2 \mathrm{c}$ & $30.7 \pm 3.1 c$ & $47.3 \pm 4.6 c$ & $38.3 \pm 2.5 c$ & $34.7 \pm 3.2 \mathrm{c}$ & $8.3 \pm 0.6 \mathrm{sc}$ & $20.0 \pm 2.6 s c$ & $15.7 \pm 4.0 \mathrm{c}$ & $39.0 \pm 8.9 c$ \\
\hline IUM 1820 & $17.3 \pm 2.5 \mathrm{c}$ & $31.3 \pm 4.7 \mathrm{c}$ & $23.0 \pm 2.6 c$ & $48.0 \pm 2.0 \mathrm{c}$ & $27.3 \pm 4.5 \mathrm{c}$ & $45.7 \pm 9.9 \mathrm{sc}$ & - & $25.3 \pm 0.6 \mathrm{sc}$ & $26.3 \pm 2.3 \mathrm{sc}$ & $24.0 \pm 1.7 \mathrm{c}$ \\
\hline
\end{tabular}

${ }^{a}$ Mean of three replications. Ala: alanine. AA: ammonium acetate. AP: ammonium phosphate. Arg: arginine. CN: calcium nitrate. Gly: glycine. His: histidine. Met: methionine. PN: potassium nitrate and Ur: urea. Each nitrogen source was added to the basal medium at the concentration of 0.02 M. c: Compact. sc: Somewhat compact. st: Somewhat thin and t: Thin

Shim et al. (2005 \& 1997) but partially similar to Shim et al. (2003). Shim et al. (2005) proved that maltose, dextrin, sucrose and mannose were effective where lactose was highly negative. Shim et al. (1997) reported that $G$. umbellata was favorable to maximum carbon sources except salicin, cellobiose and lactose. Shim et al. (2003) revealed that dextrin was suitable for mycelial growth of $P$. fumosoroseus which is not similar to our findings and they showed that in all carbon sources, mycelial density is thin where our result is opposite.

\section{Effect of nitrogen sources}

It was observed that the most suitable nitrogen sources were arginine (IUM1573 and IUM1820) and glycine (IUM0707 and IUM0756) and the most unsuitable (sometime no growth) was histidine for mycelial growth of $C$. comatus on the culture media. The highest mycelial growth of IUM0004 and IUM1544 were found 34.0 (calcium nitrate) and $87.0 \mathrm{~mm}$ (urea), respectively. On nitrogen supplemented medium, compact to thin (all kinds) mycelial density was found (Table 6). Shim et al. (2005) clarified that glycine was the most favorable and histidine, arginine and ammonium oxalate were the most unfavorable for the mycelial growth of $M$. procera on the culture media. Lee et al. (2005) showed that soytone, malt extract, yeast extract and bacto-peptone were the most favorable but NaNO3 and urea were the most unfavorable for the mycelial growth of Ramaria botrytis.

\section{CONCLUSION}

This study was conducted for the best promising fil- amentous growth and density of 6 strains of $C$. comatus. To acquire factors affecting mycelial growth and density, numerous strains of $C$. comatus were experimented. The obligation was different for the mycelial growth and density of ecologically diverse strains. Thus the basic information obtained from this study can be used for the heap manufacture of $C$. comatus.

\section{REFERENCES}

Chi, J. H., T. M. Ha, Y. H. Kim and Y. D. Rho 1996 Studies on the main factors affecting the mycelial growth of Phellinus linteus. Korean J. Mycol., 24(3): 214-222

Choi, Y. J., H. K. Hwang and W. H. Lee 1999 The production of artificial fruiting body of Paecilomyces japonica. Korean J. Mycol., 27(2): 87-93

Hutchison, L. J., S. E. Madzia and G. L. Barron 1995 The presence and antifeedent function of toxin-producing secretory cells on hyphae of the lawn-inhabiting agaric Conocybe lactea. Can. J. Bot., 74: 431-434

Jo, W. S., Y. H. Rew, S. G. Choi, G. K. Seo, J. M. Sung and J. Y. Uhm 2006 The culture conditions for the mycelial growth of Phellinus spp. Mycobiol., 34(4): 200-2005

Lee, I. K., H. J. Shim, S. D. Woo, Y. H. Je, Z. Yang and S. K. Kang 1999 Variation in growth and pathogenicity of Beauveria brassiana and Paecilomyces fumosoroseus pathogenic to the pine gall midge, Thecodiplosis japonensis. Korean J. Appl. Microb. Biotech., 27(5): 415-418

Lee, T. H. and H. H. Han 2005 Cultural characteristics for the enhanced mycelial growth of Ramaria botrytis. Mycobiol. 33(1): 12-14

Luo, H., M. Mo, X. Huang, X. Li and K. Zhang 2004 Coprinus comatus: A basidiomycete fungus forms novel spiny structures and infects nematode. Mycologia, 96(6): 1218-1225

Shim, J. O., S. G. Son, Y. H. Kim, Y. S. Lee, J. Y. Lee, T. S. Lee, S. S. Lee and M. W. Lee 1997 The culture conditions affecting the 
mycelial growth of Grifola umbellate. Korean J. Mycol., 25(3): 209-218

Shim, S. M., K. R. Lee, S. H. Kim, K H. Im, J. W. Kim, U. Y. Lee, J. O. Shim, M. W. Lee and T. S. Lee 2003 The optimal culture conditions affecting the mycelial growth and fruiting body formation of Paecilomyces fumosoroseus. Mycobiol., 31(4): 214-220

Shim, S. M., Y. H. Oh, K. R. Lee, S. H. Kim, K. H. Im, J. W. Kim, U. Y. Lee, J. O. Shim, M. J. Shim, M. W. Lee, H. S. Ro, H. S. Lee and T. S. Lee 2005 The characteristics of culture conditions for the mycelial growth of Macrolepiota procera. Mycobiol.,
33(1): 15-18

Sung, J. M., C. H. Kim, K. J. Yang, H. K. Lee and Y. S. Kim 1993 Studies on distribution and utilization of Cordyceps militaris and C. nutans. Korean J. Mycol., 21(2): 94-105

Thorn, R. G. and G. L. Barron 1984 Carnivorous mushrooms, Science, 224: 76-78

Thorn, R. G. and G. L. Barron 1986 Nematoctonus and the tribe resupinateae in Ontario, Canada. Mycotaxon, 25: 321-453

Tzean, S. S. and J. Y. Liou 1993 Nematophagous resupinate basidiomycetous fungi. Phytopathol., 83: 1015-1020 